\title{
Thermodynamics of homogeneous nucleation of ice particles in the polar summer mesosphere
}

\author{
A. Y. Zasetsky ${ }^{1}$, S. V. Petelina ${ }^{2,3}$, and I. M. Svishchev ${ }^{1}$ \\ ${ }^{1}$ Trent University, Peterborough, Ontario, Canada \\ ${ }^{2}$ La Trobe University, Victoria, Australia \\ ${ }^{3}$ Formerly at the University of Saskatchewan, Saskatoon, Canada
}

Received: 17 June 2008 - Published in Atmos. Chem. Phys. Discuss.: 30 July 2008

Revised: 15 December 2008 - Accepted: 16 January 2009 - Published: 6 February 2009

\begin{abstract}
We present the hypothesis of homogeneous nucleation of ice nano-particles in the polar summer mesosphere. The nucleation of condensed phase is traced back to the first step on the formation pathway, which is assumed to be the transition of water vapor to amorphous cluster. Amorphous clusters then freeze into water ice, likely metastable cubic ice, when they reach the critical size. The estimates based on the equilibrium thermodynamics give the critical size (radius) of amorphous water clusters as about $1.0 \mathrm{~nm}$. The same estimates for the final transition step, that is the transformation of cubic to hexagonal ice, give the critical size of about $15 \mathrm{~nm}$ at typical upper mesospheric conditions during the polar summer (temperature $T=150 \mathrm{~K}$, water vapor density $\rho_{\text {vapor }}=10^{9} \mathrm{~cm}^{-3}$ ).
\end{abstract}

\section{Introduction}

Observable in the polar summer mesosphere, typically poleward of $50^{\circ}$, Polar Mesospheric Clouds (PMCs) are a population of nano-sized crystalline $\mathrm{H}_{2} \mathrm{O}$ particles that form at heights of 82 to $86 \mathrm{~km}$. It has been suggested that the longterm trends in PMC properties, such as the cloud brightness and occurrence rate, may be related to climate change (Deland et al., 2003; Thomas, 1991).

Although our knowledge of the upper mesospheric region in general and PMC properties in particular is continuously improving due to the ever increasing capabilities and sophistication of atmospheric models, remote sensing observations, and laboratory experiments; many aspects of mesospheric

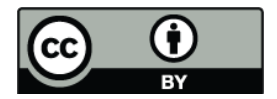

Correspondence to: S. Petelina

(s.petelina@latrobe.edu.au) dynamics and thermodynamics are still unclear. The nucleation rates predicted by classical nucleation theory $(\mathrm{CNT})$ reveal systematic discrepancies from those experimentally observed at somewhat higher temperatures (Viisanen et al., 1993), and we expect the deviations to be much higher under mesospheric conditions. The difficulties in predicting the characteristics of ice particles in the polar summer mesosphere result also from large experimental errors in the saturated vapor pressure of water over ice, and in its temperature dependence in particular, as well as the uncertainties in the dynamics of sedimentation and coagulation of these particles (Rapp and Lübken, 2004).

Heterogeneous nucleation is typically used in atmospheric models. For this mechanism to be applicable a significant concentration of pre-existing particles (seeds) is needed. Note that it is always advantageous to consider a barrier-free condensation of supersaturated water vapor since it occurs on the surface of large enough seeds, and no work has to be done to build a new phase. However, in the recently published review on mesospheric ice nucleation (Rapp and Thomas, 2006), the authors argue that "... several candidates for these particles (seeds) have been proposed. However, to date, there is no convincing experimental evidence for any of these possibilities." On the other hand, recent developments in the nucleation theory point to the possibility of a nucleation scenario for PMC particles based on homogeneous nucleation.

Motivated by this, we address some of the open questions related to the thermodynamics of water at the conditions intrinsic for the polar summer mesosphere with the emphasis on the homogeneous nucleation of PMC ice particles. For this we use recently published theoretical and laboratory results on the properties of water at very low temperatures. These results are briefly outlined below. 
First, the PMC ice particles nucleation pathway may not necessarily be a direct transition from saturated water vapor to stable hexagonal ice. It was suggested as early as in 1897 (Ostwald, 1897) that a phase transformation can be stepwise; specifically, it may proceed via several steps that include intermediate (and possibly metastable) phases before reaching a final thermodynamically stable phase.

Second, in agreement with the above concept, the experimental studies (Devlin and Buch, 1997; Devlin et al., 2000) show that very small water clusters, on the order of 100 molecules, are amorphous. The first nucleated phase in the mesosphere, therefore, is assumed to be amorphous water clusters.

Third, it was shown that, when account is taken of realistic (with a finite thickness) interfaces between vapor and condense phases, the rate of gas-to-condense phase nucleation is noticeably higher (Laaksonen and McGraw, 1996; McGraw and Laaksonen, 1997). Since amorphous cluster have seemingly diffuse interfaces, this effect is clearly applicable to the formation characteristics of water clusters in the mesosphere.

The hypothesis of surface stimulated freezing transition is the final argument in favor of the multi-steps homogeneous PMC nucleation. Here the hypothesis is considered in connection to the amorphous-to-crystal transition. It is based on the suggestion that the height of free energy barrier is lower near vapor - condense phase interfaces. This reduction in the free energy barrier height for the critical nuclei formation can significantly alter (increase) the nucleation rate (Djikaev et al., 2000).

In the following sections we discuss the above mentioned theories, assumptions, and observations in conjunction with the thermodynamics of water in the polar summer mesosphere. Atmospheric parameters used in our simulations, namely values for water vapor densities and temperatures, are those measured by the ongoing satellite mission Atmospheric Chemistry Experiment Fourier Transform Spectrometer (ACE-FTS) (Bernath et al., 2005; Boone et al., 2005). The recent validation results for these parameters yield an error in the temperature retrievals of less than $2 \mathrm{~K}$ below $70 \mathrm{~km}$ and less than $8 \mathrm{~K}$ near the mesopause altitudes (Sica et al., 2008). Water vapor concentration retrievals are better than $5 \%$ from 15 to $70 \mathrm{~km}$ and better than $10 \%$ at PMC altitudes (Carleer et al., 2008).

PMC particle number densities have also been calculated from ACE-FTS measurements of more than 200 clouds. These values vary between 20 and $130 \mathrm{~cm}^{-3}$ and are in a good agreement with the findings of Baumgarten et al. (2008) based on 10 years of ground-based lidar measurements of PMCs over ALOMAR in northern Norway $\left(69^{\circ} \mathrm{N}, 16^{\circ} \mathrm{E}\right)$. In the above work, the values for mesospheric ice number density were found to be between 33 and $105 \mathrm{~cm}^{-3}$. We note that ACE-FTS is currently the only instrument that provides simultaneous measurements of PMCs and reliable upper mesospheric temperature and water vapor concentrations. Another instrument with such capabilities, Solar Occultation for Ice
Experiment (SOFIE) on Aeronomy of Ice in the Mesosphere (AIM), has been launched in 2007. The work to retrieve upper mesospheric temperatures and water vapor density coincident with PMCs from the AIM data is currently underway.

\section{PMC formation scenario}

Ten Volde and Frenkel (1999) have recently reminded us of the Ostwald step rule (Ostwald, 1897), which implies that the phase that nucleates first may not be the most stable but one with a somewhat lower free energy barrier. The present paper describes an attempt to solve the mystery of ice particle formation in the mesosphere by applying this rule in the framework of homogeneous nucleation. We suggest that the entire cloud formation process consists of several steps. The first step on the pathway to forming a cloud is the nucleation of small amorphous water clusters that consist nearly only of the surface molecules (Devlin and Buch, 1997; Devlin et al., 2000). Thus critical nuclei at the stage of gas-to-amorphous transition are amorphous water particles whose structure is substantially different from the structure of the final ice particles. The amorphous-to-crystal transition is the next step. Since it has been recently demonstrated on a thermodynamic basis (Johari, 2005) that ice particles smaller than $\sim 15 \mathrm{~nm}$ can freeze to cubic ice, we speculate that the next phase, which is also metastable, is cubic ice. The next nucleation step is the transition to hexagonal ice that is the most stable ice polymorph at these atmospheric conditions.

Summarizing our hypotheses, we suggest that the process of PMC formation is diffusive, i.e., the sequence of transitions through reduced energy barriers rather than an activated transition over a high barrier in a single step as it is assumed in the case of direct gas-to-ice nucleation. The mechanism of cloud formation can thus be given as follows:

Supersaturated vapor $\rightarrow$ Amorphous cluster $(\sim 1 \mathrm{~nm}) \rightarrow$ Cubic ice $(>1 \mathrm{~nm}) \rightarrow$ Hexagonal ice $(>15 \mathrm{~nm})$

The final stage that follows logically from this scenario is the growth of ice particles until water vapor comes to the equilibrium with nucleated ice.

\section{Gas-to-amorphous nucleation (Laaksonen - McGraw formulation)}

Departing from a non-uniform droplet model of critical nuclei Romero-Rochin and Percus (1996) and the Kelvin relation, Laaksonen and McGraw (1996) and McGraw and Laaksonen (1997) showed that the predictions of classical nucleation theory, which are "... insufficient for the quantitative prediction of the rate of nucleation" (Adams et al., 1984; Viisanen et al., 1993), can be considerably improved. This elaboration of CNT predicts a reduction in the nucleation barrier height with the free energy of interfacial curvature (McGraw and Laaksonen, 1997). The diffuse droplet model, i.e., droplets in which the interface has a smoothly 


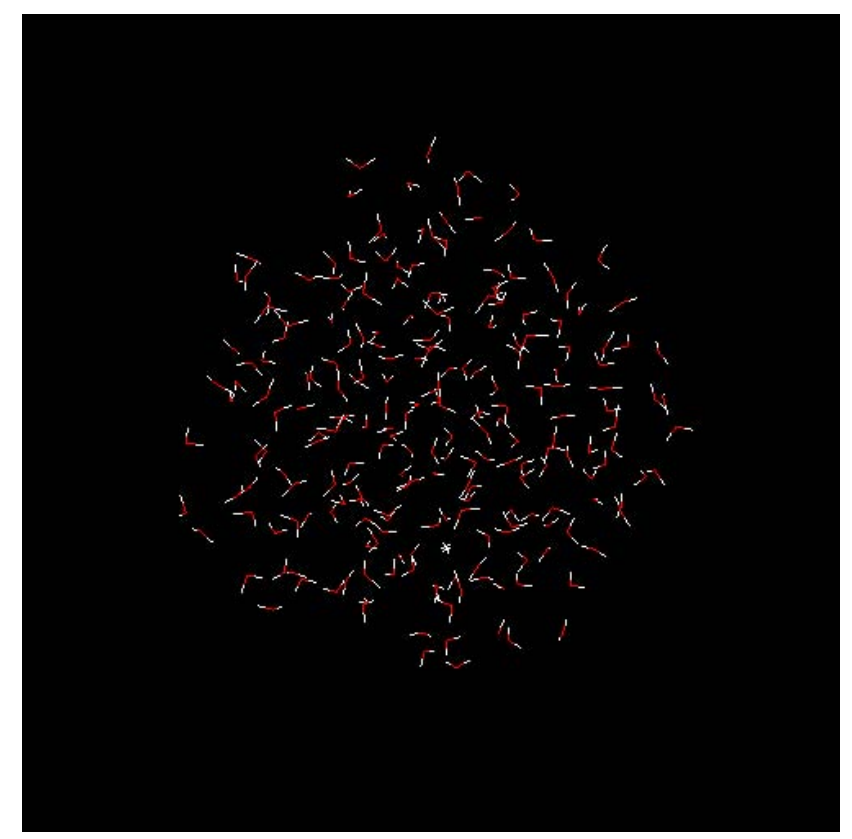

Fig. 1. Snapshot of a water cluster composed of 244 molecules simulated with "vacuum" boundary conditions at $120 \mathrm{~K}$.

varying density profile and a finite thickness, is consistent with the gas-to-amorphous or even gas-to-crystal transition of water, as even the interface of ice particles appears to have a quasi-liquid interfacial layer of finite thickness (Henson et al., 2005). We performed molecular dynamics (MD) simulations of water clusters at the mesospheric conditions using the method utilized in (Zasetsky et al., 2007). In the present work, MD simulations were carried out in the NVT ensemble (isochoric - isothermal conditions) with temperature controlled by the Nosé-Hoover thermostat (Nose, 1984). The simple point charge extended (SPC/E) model by Berendsen et al. (1987) for the water-water interaction was used. The equations of motion were integrated using the Verlet leap frog algorithm with the SHAKE constraints technique without any special treatment for long range electrostatic interactions ("vacuum" simulations) and a time step of 2 fs. Liquid water was originally prepared in the standard bulk simulations (Allen and Tildesley, 1987) at room temperature. Spherical liquid particles were then cut out and placed in a large simulation box. The particles were equilibrated at the reduced temperature of $120-150 \mathrm{~K}$ for one nanosecond before sampling over the time period of $100 \mathrm{~ns}$ any properties (such as the density profile used in this work). Figure 1 illustrates a typical amorphous water particle at a temperature of $120 \mathrm{~K}$. The simulations were performed to obtain realistic density profiles for interfaces between water vapor and amorphous clusters. The average density profile for this particle is shown in Fig. 2. These simulation results prove that the interface is diffuse, with the thickness of about 8-10 Ångstrom.

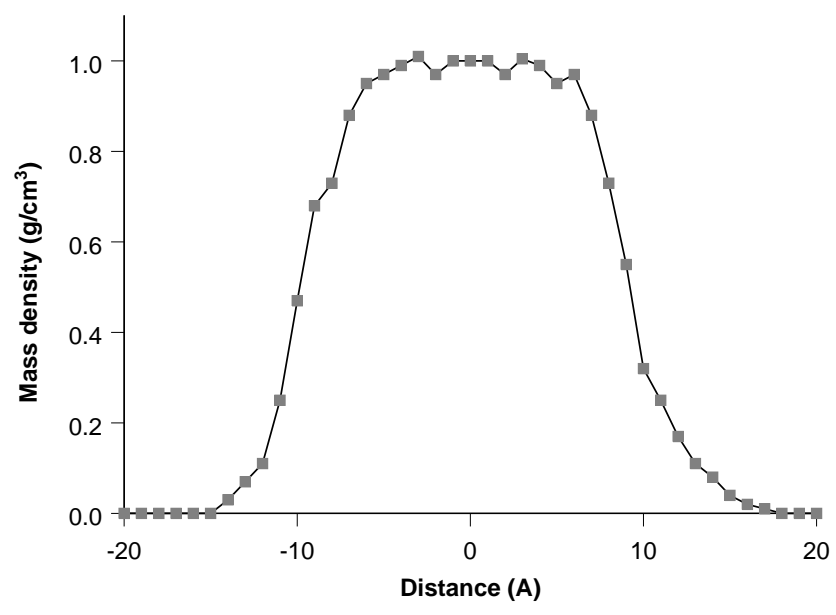

Fig. 2. Mass density profile for amorphous cluster of 244 water molecules obtained by molecular dynamic simulations at $120 \mathrm{~K}$.

Accordingly, the Gibbs free formation energy for a droplet with a diffuse interface as a function of particle radius $r$ can be written as

$$
\begin{aligned}
& \Delta G_{\mathrm{vap} \rightarrow A W}(r)=4 \pi r^{2}\left(\gamma_{\infty}+\frac{K_{s}}{r^{2}}+\ldots\right)- \\
& \frac{4 \pi \rho_{A W} r^{3} k T \ln (S)}{3 m_{\mathrm{H}_{2} \mathrm{O}}}
\end{aligned}
$$

Here, the subscript (vap $\rightarrow A W$ ) refers to the transition from water vapor to condense amorphous particles, $\gamma_{\infty}$ is the surface tension of a flat interface, $\rho$ is the (mass) density, $S$ is the vapor saturation ratio, $m_{\mathrm{H}_{2} \mathrm{O}}$ is the mass of molecule, and $K_{s}$ is the rigidity coefficient (which gives the scaling of $K_{s} / r^{2}$ ).

Since we assume that the first step in PMC formation is the nucleation of small (nanometers) amorphous water clusters from saturated vapor, the density of amorphous water $\rho_{A W}=0.94 \mathrm{~g} / \mathrm{cm}^{3}$ is used. The value of the bulk surface tension, $\gamma_{\infty}$, is taken from (Hruby and Holten, 2004). The rigidity coefficient $K_{s}$ for water at the mesospheric temperatures is not known. Our calculations based on the results of molecular dynamics simulations give the rigidity coefficient value as $K_{s} \approx-0.9 k T$. This is in a good agreement with calculations for simple (Lennard-Jones) systems (Laaksonen and McGraw, 1996; McGraw and Laaksonen, 1997), which give $K_{s} \approx-k T$. This relatively small reduction in the nucleation barrier height is enough to increase the nucleation rate $J$ by 3 orders of magnitude in comparison to that of CNT, $J / J_{\mathrm{CNT}} \approx e^{3 \pi} \approx 2 \times 10^{3}$, making the hypothesis of homogeneous nucleation of water vapor to amorphous particles in the mesosphere plausible.

The calculated dependence of the Gibbs free formation energy on the particle radius is shown in Fig. 3. Apparently the realistically low values of the saturation ratio, $S$, in view of large temperature gradients and water vapor density fluctuations in the mesosphere, are required to shift the radius of 


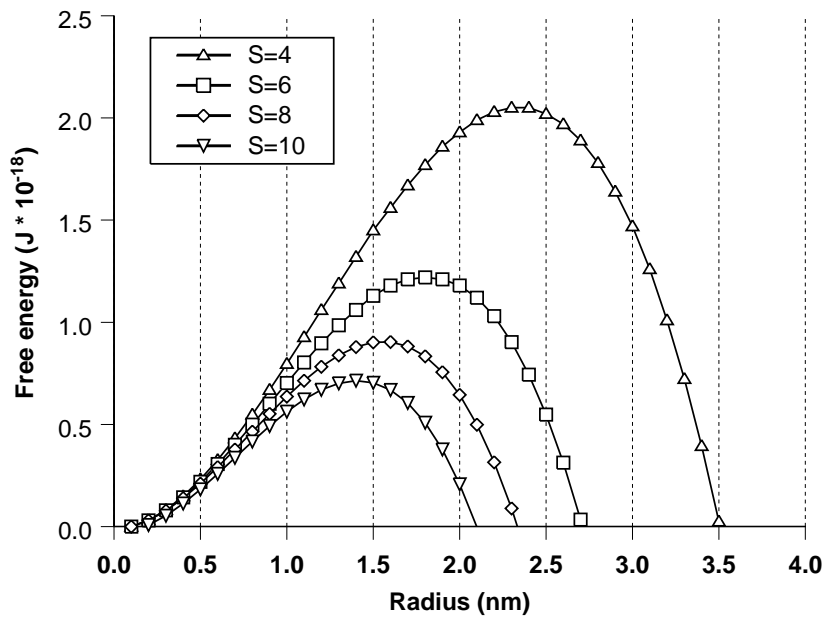

Fig. 3. Free formation energy of amorphous water droplets as a function of their size at $120 \mathrm{~K}$ (calculated using Eq. 1).

critical nuclei to a scale of 1 nanometer. We have computed the saturated water vapor pressure over ice by using the relation from (Murphy and Koop, 2005) and the ACE-FTS level 2 data for $T$ and water vapor density. The calculation results, shown in Fig. 4, imply that at temperatures below $145 \mathrm{~K}$ the $S$ values are in the range suitable for PMC formation, between 1 and $10^{3}$. These $T$ values agree well with the upper mesospheric frost point temperature of about $150 \mathrm{~K}$ obtained with various ground-based and satellite instruments (e.g. Lübken, 1999; Petelina et al., 2005). We note that the uncertainty in temperature of up to $\pm 8 \mathrm{~K}$ and uncertainty in water vapor concentration of up to $\pm 10 \%$ result in the error in $S$ of about $300 \%$.

The equilibrium vapor pressure over ice can be approximated, according to the experimental data provided by Lide (1999), by the following relation: $P_{\mathrm{eq}} \propto\left\{\left(T-T_{0}\right) / C\right\}^{12}$. Here $C$ is the difference between boiling point and melting point: $C \approx 373 \mathrm{~K}-273 \mathrm{~K}$, and $T_{o}=136 \mathrm{~K}$ is the temperature of the phase transition between glassy amorphous ice and deeply supercooled amorphous water. We note that this is a very steep function of $T$ and a relatively small uncertainty in the retrieved temperature, therefore, translates into large errors in the water vapor pressure.

\section{Critical size of amorphous clusters}

In order to determine the critical size of amorphous clusters, we use the approach described in (Johari, 2005). In the language of classical equilibrium thermodynamics, the difference in Gibbs free formation energy for particles in amorphous (AW) and crystalline (Ice) states is given by the following relation (see Eq. 1 in Johari, 2005):

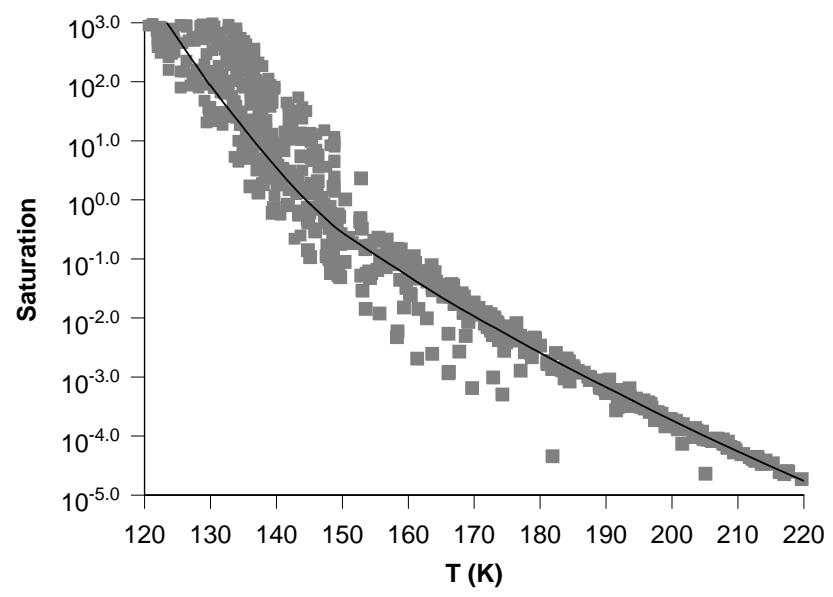

Fig. 4. Water vapor saturation ratio at mesospheric altitudes computed from ACE-FTS observations.

$\Delta G_{A W \rightarrow \text { Ice }}=\Delta H_{A W \rightarrow \text { Ice }}-T \Delta S_{A W \rightarrow \text { Ice }}+$

$\left(\gamma_{\text {Ice }}-\gamma_{A W}\right) A$

where $\Delta H$ and $\Delta S$ are the differences in molar enthalpy and entropy, respectively; $\gamma_{A W}$ and $\gamma_{\text {Ice }}$ are the values of surface tension for amorphous water and ice; $A$ is the surface area of the particle, and $T$ is the temperature.

Equation (2) can be further explained in terms of molar values (denoted with tilde), differences between vapor and ice phase $(\Delta)$, and differences between phases, i.e. amorphous and crystalline ice $(\delta)$ :

$$
\begin{array}{lll}
\delta(\Delta \tilde{G})_{A W \rightarrow \text { ice }} & =\Delta \tilde{G}_{\mathrm{vap} \rightarrow \text { ice }} & -\Delta \tilde{G}_{\mathrm{vap} \rightarrow A W}, \\
\delta(\Delta \tilde{H})_{A W \rightarrow \text { ice }} & =\Delta \tilde{H}_{\mathrm{vap} \rightarrow \text { ice }} & -\Delta \tilde{H}_{\mathrm{vap} \rightarrow A W}, \\
\delta(\Delta \tilde{S})_{A W \rightarrow \text { ice }} & =\Delta \tilde{S}_{\mathrm{vap} \rightarrow \text { ice }} & -\Delta \tilde{S}_{\mathrm{vap} \rightarrow A W}, \\
\delta(\Delta \tilde{G})_{A W \rightarrow \text { ice }}^{0} & =\delta(\Delta \tilde{H})_{A W \rightarrow \text { ice }}-\delta(T \Delta \tilde{S})_{A W \rightarrow \text { ice }}, \\
\delta \gamma & =\gamma_{\mathrm{vap} / \text { ice }} & -\gamma_{\mathrm{vap} / A W}
\end{array}
$$

Here, the term $\delta(\Delta \tilde{G})_{A W \rightarrow \text { ice }}^{0}$ refers to the differences between the corresponding free enthalpies, $\gamma_{\mathrm{vap} / A W}$ denotes the surface tension of the vapour/amorphous ice interface, and $\gamma_{\text {vap/ice }}$ is the surface tension of the vapour/crystalline ice interface. Equation (2) can now be rewritten as:

$$
\begin{aligned}
& \delta(\Delta \tilde{G})_{A W \rightarrow \text { ice }}=\delta(\Delta \tilde{G})_{A W \rightarrow \text { ice }}^{0}+\beta A \delta \gamma, \\
& \beta=\frac{m_{\mathrm{H}_{2} \mathrm{O}} N_{A}}{\frac{4}{3} \pi r^{3} \rho_{A W}}=\frac{v_{\mathrm{H}_{2} \mathrm{O}} N_{A}}{\frac{4}{3} \pi r^{3}}=\frac{M_{\mathrm{H}_{2} \mathrm{O}}}{m}=\frac{N_{A}}{n}
\end{aligned}
$$

Here $m_{\mathrm{H}_{2} \mathrm{O}}$ is the mass of one water molecule, $v_{\mathrm{H}_{2} \mathrm{O}}$ is the volume occupied by a water molecule in the corresponding ice cluster, $M_{\mathrm{H}_{2} \mathrm{O}}$ is the molar mass of water, $m$ is the mass of the droplet (embryo of the new phase) of radius $r$, $n=m / m_{\mathrm{H}_{2} \mathrm{O}}$ is the number of water molecules in the droplet, and $N_{A}$ is the Avogadro constant. 
Considering $A=4 \pi r^{2}$ and requiring

$\delta(\Delta \tilde{G})_{A W \rightarrow \text { Ice }}=0$

we obtain the critical radius:

$r_{c}=-\left(\frac{3 m_{\mathrm{H}_{2} \mathrm{O}} N_{A}}{\rho_{A W}}\right) \frac{\delta \gamma}{\delta(\Delta \tilde{G})_{A W \rightarrow \text { ice }}^{0}}$

Inserting (6) into (2) gives

$\delta(\Delta \tilde{G})_{A W \rightarrow \text { ice }}=\delta(\Delta \tilde{G})_{A W \rightarrow \text { ice }}^{0}\left(1-\frac{r_{c}}{r}\right)$

As follows from the experimental results and will be referenced later, $\delta(\Delta \tilde{H})_{A W \rightarrow \text { ice }}<0$ and $\delta(\Delta \tilde{S})_{A W \rightarrow \text { ice }}>0$. Thus $(\Delta \tilde{G})_{A W \rightarrow \text { ice }}^{0}<0$ and Eq. (7) can be rewritten as

$\delta(\Delta \tilde{G})_{A W \rightarrow \text { ice }}=\left|\delta(\Delta \tilde{G})_{A W \rightarrow \text { ice }}^{0}\right|\left(1-\frac{r_{c}}{r}\right)$

According to (8), it is thermodynamically favorable for the particles to be in the amorphous state when $r<r_{c}$, i.e. $\delta(\Delta \tilde{G})_{A W \rightarrow \text { ice }}>0$, and in the crystalline state if $r>r_{c}$ and thus $\delta(\Delta \tilde{G})_{A W \rightarrow \text { ice }}<0$.

We computed the critical radius in (6) using the following experimental data: $\Delta H_{A W \rightarrow \mathrm{Ice}}=-1.29 \mathrm{~kJ} / \mathrm{mol}$ (Hallbrucker et al., 1989), the surface tension for amorphous water $\gamma_{A W}=0.088-0.092 \mathrm{~J} / \mathrm{m}^{2}$ and ice $\gamma_{\text {Ice }}=0.122 \mathrm{~J} / \mathrm{m}^{2}$ from (Hruby and Holten, 2004) and (Hale and Plummer, 1974), respectively, and the difference in the molar entropy of $\Delta S_{A W \rightarrow \text { Ice }} \approx 1.7 \mathrm{~J} \mathrm{~mol}^{-1} \mathrm{~K}^{-1}$ (Speedy et al., 1996). The density of amorphous water is equal to $0.94 \mathrm{~g} / \mathrm{cm}^{3}$. Using a temperature of $150 \mathrm{~K}$ and taking account of the reported uncertainties, we find the critical particle radius to be on the order of $1 \pm 0.5 \mathrm{~nm}$.

This is in good agreement with infrared studies of large water clusters that are produced by fast expansion of a mixture of water-He vapor in vacuum (Devlin and Buch, 1997; Devlin et al., 2000). Note that the temperature reported in the above cited works is about $100 \mathrm{~K}$, which is even lower than that at the coldest conditions in the mesosphere. Devlin et al. (2000) have convincingly shown that the crystalline core (bulk crystalline ice) contributions to the IR intensities are only distinguishable for relatively large particles and vanish for particles with the radius less than $1.5 \mathrm{~nm}$. This indicates the presence of the interface between the bulk core and surrounding vapor thus providing the basis for the diffuse droplet model (Laaksonen and McGraw, 1996). It is also in agreement with our assumption that the first nucleated phase is amorphous water particles with a critical radius of about $1 \mathrm{~nm}$.

\section{Critical size for cubic to hexagonal ice transition}

Based on the thermodynamics of water at lower temperatures, Johari (2005) has recently shown that the critical radius for ice particles to transform from cubic to hexagonal ice is approximately $15 \mathrm{~nm}$ in the temperature region between 160 and $200 \mathrm{~K}$. This result suggests that the particles with sizes smaller than $15 \mathrm{~nm}$ freeze in the cubic form of ice, whereas for bigger particles it is thermodynamically preferable to exist as hexagonal ice. We should note that, because of a small volume of particles, this transition may take a very long time to occur at the temperatures typical for PMC formation events (this state is sometimes referred as a "kinetically stable").

\section{Conclusion}

The present work is focused on the thermodynamic aspects of the formation of ice particles at typical polar summer mesospheric conditions. We introduce a scenario of ice particle formation based on homogenous nucleation and describe a particle formation pathway which makes this hypothesis feasible, subject to some conditions. The central assumption is that the particle formation occurs in several steps. Specifically, the system overcomes several barriers with reduced heights. This is rather different from the commonly discussed (but not yet confirmed) scenario of a direct transition of saturated water vapor to crystalline hexagonal ice (Murphy, 2003). The latter results suggest that the transition time is too long to be of any relevance for mesospheric conditions.

The amorphous water particles - clusters that consist of $10^{2}$ to $10^{3}$ water molecules - are considered to be critical nuclei for the first nucleated phase. Attention is drawn to a recent development in nucleation theory that predicts substantial reduction in the height of a free energy barrier for particles with realistic structures of the gas-condense phase interface (Laaksonen and McGraw, 1996; McGraw and Laaksonen, 1997). To avoid ambiguity, a critical radius of the amorphous particles was computed using the ACE-FTS measurements of water vapor and temperature. The resulting value for the critical radius of $1 \pm 0.5 \mathrm{~nm}$ is in good agreement with the results of an infrared study of water clusters (Devlin and Buch, 1997; Devlin et al., 2000). As for a possibility for cubic ice formation, this could be the next nucleated phase, which is reported to be thermodynamically stable for the particles with the radius $<15 \mathrm{~nm}$ (Johari, 2005). Hexagonal ice is assumed to be the final nucleated phase.

In addition to the thermodynamics and kinetics of pure $\mathrm{H}_{2} \mathrm{O}$, we should mention the potential effect of impurities, such as meteoritic dust (Plane, 2003) and/or atomic metals such as $\mathrm{Fe}, \mathrm{Na}, \mathrm{K}$, on the speed of particle formation and growth. The contamination of the PMC particle interface with these substances is known to affect the surface excess free energy. Although this effect will clearly depend on the type of impurities, a reduction in the height of a nucleation barrier is expected in any case. The evidence for the removal of Fe atoms by PMC particles has been recently reported (Plane et al., 2004). Considering the significant sticking probability of atomic $\mathrm{Fe}$ and $\mathrm{Na}$ on the surface of ice 
particles at lower temperatures, it is reasonable to expect a reduction in the surface tension value due to their uptake and thus a further increase in the nucleation rate.

We emphasize again that the hypothesis of homogeneous nucleation of ice particles in the polar summer mesosphere described in this work is yet to be confirmed or denied. Laboratory studies on the low temperature ice nucleation are needed to improve our understanding of the nucleation kinetics. Satellite, ground based, and in-situ observations of mesospheric water fill a gap in experimental studies and help to improve our understanding of fundamental thermodynamics and kinetics of water at such low temperatures. Cubic ice may be kinetically stable at the mesospheric conditions. In other words it may require very long time to transform into the stable hexagonal form and thus be a main component of PMCs at some conditions. However, to the best of our knowledge, any accurate visible, infrared, or microwave spectra for cubic ice (or any difference from hexagonal) have not yet been reported and, therefore, there have not been any successful attempts to distinguish cubic ice from hexagonal ice based on optical measurements. The kinetic aspects of ice freezing, which control the transition of amorphous-to-cubic and cubic-to-hexagonal ice, as well as the effect of impurities on the nucleation kinetics, require additional studies.

Acknowledgements. The financial support for this work was provided by the Natural Sciences and Engineering Research Council of Canada and the Canadian Space Agency. The Atmospheric Chemistry Experiment (ACE), also known as SCISAT, is a Canadian-led mission mainly supported by the Canadian Space Agency (CSA) and the Natural Sciences and Engineering Research Council of Canada (NSERC). ACE-FTS data are currently provided by the European Space Agency.

Edited by: F.-J. Lübken

\section{References}

Adams, G. W., Schmitt, J. L., and Zalabsky, R. A.: The Homogeneous nucleation of nonane, J. Chem. Phys., 81, 5074-5078, 1984.

Allen, M. P. and Tildesley, D. J.: Computer Simulation of Liquids, Clarendon Press, Oxford, 385 pp., 1987.

Baumgarten, G. K., Fiedler, J., Lübken, F.-J., and von Cossart, G.: Particle properties and water content of noctilucent clouds and their interannual variations, J. Geophys. Res., 113, D06203, doi:10.1029/2007JD008884, 2008.

Bernath, P. F., McElroy, C. T., Abrams, M. C., Boone, C. D., Butler, M., Camy-Peyret, C., Carleer, M., Clerbaux, C., Coheur, P. F., Colin, R., DeCola, P., Bernath, P. F., McElroy, C. T., Abrams, M. C., Boone, C. D., Butler, M., Camy-Peyret, C., Carleer, M., Clerbaux, C., Coheur, P. F., Colin, R., DeCola, P., DeMaziere, M., Drummond, J. R., Dufour, D., Evans, W. F. J., Fast, H., Fussen, D., Gilbert, K., Jennings, D. E., Llewellyn, E. J., Lowe, R. P., Mahieu, E., McConnell, J. C., McHugh, M., Mcleod, S. D., Michaud, R., Midwinter, C., Nassar, Nichitiu, F., Nowlan, C., Rinsland, C. P., Rochon, Y. J., Rowlands, N., Semeniuk, K.,
Simon, P., Skelton, R., Sloan, J. J., Soucy, M. A., Strong, K., Tremblay, P., Turnbull, D., Walker, K. A., Walkty, I., Wardle, D. A., Wehrle, V., Zander, R., and Zou, J.: Atmospheric Chemistry Experiment (ACE): Mission overview, Geophys. Res. Lett., 32, L15S01, doi:10.1029/2005GL022386, 2005.

Berendsen, H. J. C., Grigera, J. R., and Straatsma, T. P. J.: The missing term in effective pair potential, Phys. Chem., 91, 62696271, 1987.

Boone, C. D., Nassar, R., Walker, K. A., Rochon, Y., Mcleod, S. D., Rinsland, C.P., and Bernath, P. F.: Retrievals for the atmospheric chemistry experiment Fourier-transform spectrometer, Appl. Opt., 44, 7218-7231, 8445, doi:10.1029/2002JD002398, 2005.

Carleer, M. R., Boone, C. D., Walker, K. A., Bernath, P. F., Strong, K., Sica, R. J., Randall, C. E., Vömel, H., Kar, J., Höpfner, M., Milz, M., von Clarmann, T., Kivi, R., ValverdeCanossa, J., Sioris, C. E., Izawa, M. R. M., Dupuy, E., McElroy, C. T., Drummond, J. R., Nowlan, C. R., Zou, J., Nichitiu, F., Lossow, S., Urban, J., Murtagh, D., and Dufour, D. G.: Validation of water vapour profiles from the Atmospheric Chemistry Experiment (ACE), Atmos. Chem. Phys. Discuss., 8, 4499-4559, 2008 ,

http://www.atmos-chem-phys-discuss.net/8/4499/2008/.

Deland, M. T., Shettle, E. P., Thomas, G. E., and Olivero, J. J.: Solar backscattered ultraviolet (SBUV) observations of polar mesospheric clouds (PMCs) over two solar cycles, J. Geophys. Res., 108(D8), 8445, doi:10.1029/2002JD002398, 2003.

Devlin, J. P. and Buch, V.: Vibrational spectroscopy and modeling of the surface and subsurface of ice and of ice-adsorbate interactions, J. Phys. Chem., B, 101, 6095-6098, 1997.

Devlin, J. P., Joyce, C., and Buch, V.: Infrared spectra and structures of large water clusters, J. Phys. Chem. A, 104, 1974-1977, 2000.

Djikaev, Y. S., Tabazadeh, A., Hamill, P., and Reiss, H. J.: Thermodynamic conditions for the surface-stimulated crystallization of atmospheric droplets, J. Phys. Chem. A, 106, 10247, doi:10.1021/jp021044s, 2002.

Eremenko, M. N., Petelina, S. V., Zasetsky, A. Y., Karlsson, B., Rinsland, C. P., Llewellyn, E. J., and Sloan, J. J.: Shape and composition of PMC particles derived from satellite remote sensing measurements, Geophys. Res. Lett., 32, L16S06, doi:10.1029/2005GL023013, 2005.

Hale, B. N. and Plummer, P. L. M.: Molecular model for ice clusters in a supersaturated vapor, J. Chem. Phys., 61, 4012-4019, 1974.

Hallbrucker, A., Mayer, E., and Johari, G. P.: Glass-liquid transition and the enthalpy of devitrification of annealed vapordeposited amorphous solid water - a comparison with hyperquenched glassy water, J. Phys. Chem., 93, 4986-4990, 1989.

Henson, B. F., Voss, L. F., Wilson, K. R., and Robinson, J. M.: Thermodynamic model of quasiliquid formation on $\mathrm{H}_{2} \mathrm{O}$ ice: Comparison with experiment, J. Chem. Phys., 123, 144707, doi:10.1063/1.2056541, 2005.

Hruby, J. and Holten, V.: A two-structure model of thermodynamic properties and surface tension of supercooled water, 14th Conference on Properties of Water and Steam, Kyoto, 241-246, 2004.

Johari, G. P.: Water's size-dependent freezing to cubic ice, J. Chem. Phys., 122, 194504, doi:10.1063/1.1900723, 2005.

Laaksonen, A. and McGraw, R.: Thermodynamics, gas-liquid nucleation, and size-dependent surface tension, Europhys. Lett., 35, 367-372, 1996. 
Lide, R.: CRC Handbook of chemistry and physics, 80th Ed., CRC Press, Boca Raton, FL, USA, 2504 pp., 1999.

Lübken, F.-J.: Thermal structure of the Arctic summer mesosphere, J. Geophys. Res., 104, 9135-9149, 1999.

McGraw, R. and Laaksonen, A.: Interfacial curvature free energy, the Kelvin relation, and vapor-liquid nucleation rate, J. Chem. Phys., 106, 5284-5287, 1997.

Murphy, D. M.: Dehydration in ice clouds is enhanced by transition from cubic to hexagonal ice, Geophys. Res. Lett., 30, 2230, doi:10.1029/2003GL018566, 2003.

Murphy, D. M. and Koop, T.: Review of the vapour pressures of ice and supercooled water for atmospheric applications, Quarterly Journal of the Royal Meteorological Society, 131, 1539-1565, 2005.

Nose, S.: A molecular dynamics method for simulations in the canonical ensemble, Mol. Phys., 52, 255-268, 1984.

Ostwald, W: Studien uber die Bildung und Umwandlung fester Korper, Z. Phys. Chem., 22, 289-302, 1897.

Petelina, S. V., Degenstein, D. A., Llewellyn, E. J., Lloyd, N. D., Mertens, C. J., Mlynczak, M. G., and Russell, J. M.: Thermal conditions for PMC existence derived from Odin/OSIRIS and TIMED/SABER data, Geophys. Res. Lett., 32, L17813, doi:10.1029/2005GL023099, 2005.

Plane, J. M. C.: Atmospheric chemistry of meteoric metals, Chem. Rev., 103, 4963-4984, 2003.

Plane, J. M. C., Murray, B. J., Chu, X. Z., and Gardner, C. S.: Removal of meteoric iron on polar mesospheric clouds, Science, 304, 426-428, 2004.

Rapp, M. and Lübken, F.-J.: Polar mesosphere summer echoes (PMSE): review of observations and current understanding, Atmos. Chem. Phys., 4, 2601-2633, 2004, http://www.atmos-chem-phys.net/4/2601/2004/.
Rapp, M. and Thomas, G. E.: Modeling the microphysics of mesospheric ice particles: Assessment of current capabilities and basic sensitivities, Journal of Atmospheric and Solar-Terrestrial Physics, 68(7), 715-744, 2006.

Romero-Rochin, V. and Percus, J. K.: Stress tensor of liquid-vapor states of inhomogeneous fluids, Phys. Rev. E, 53, 5130-5136, 1996.

Sica, R. J., Izawa, M. R. M., Walker, K. A., Boone, C., Petelina, S., Argall, P. S., Bernath, P., Burns, G. B., Catoire, V., Collins, R. L., Daffer, W. H., De Clercq, C., Fan, Z. Y., Firanski, B. J., French, W. J. R., Gerard, P., Gerding, M., Granville, J., Innis, J. L., Keckhut, P., Kerzenmacher, T., Klekociuk, A. R., Kyrö, E., Lambert, J. C., Llewellyn, E. J., Manney, G. L., McDermid, I. S., Mizutani, K., Murayama, Y., Piccolo, C., Raspollini, P., Ridolfi, M., Robert, C., Steinbrecht, W., Strawbridge, K. B., Strong, K., Stübi, R., and Thurairajah, B.: Validation of the Atmospheric Chemistry Experiment (ACE) version 2.2 temperature using ground-based and space-borne measurements, Atmos. Chem. Phys., 8, 35-62, 2008, http://www.atmos-chem-phys.net/8/35/2008/.

Speedy, R. J., Debenedetti, P. G., Smith, R. S., Huang, C., and Kay, B. D.: The evaporation rate, free energy, and entropy of amorphous water at $150 \mathrm{~K}$, J. Chem. Phys., 105, 240-244, 1996.

ten Wolde, P. R. and Frenkel, D.: Homogeneous nucleation and the Ostwald step rule, Phys. Chem. Chem. Phys., 1, 2191-2196, 1999.

Thomas, G. E.: Mesospheric clouds and the physics of the mesopause region, Rev. Geophys., 29, 553-575, 1991.

Viisanen, Y., Strey, R., and Reiss, H.: Homogeneous nucleation rates for water, J. Chem. Phys., 99, 4680-4692, 1993.

Zasetsky, A. Y., Remorov, R., and Svishchev, I. M.: Evidence of enhanced local order in supercooled water near liquid-vapor interface: Molecular dynamic simulations, Chem. Phys. Lett., 435(13), 2007. 